\section{Impact of COVID-19 pandemic}

\section{on anti-microbial resistance and secondary microbial infections}

\author{
KP Mishra ${ }^{1 *}$, Priyanka Mishra ${ }^{2}$, AK Singh ${ }^{1}$ and SB Singh ${ }^{3}$ \\ 'Defence Research and Development Organization-HQ, Delhi, India \\ ${ }^{2}$ Defence Institute of Physiology and Allied Sciences (DIPAS, DRDO) Delhi, India \\ ${ }^{3}$ National Institute of Pharmaceutical Education and Research (NIPER), Hyderabad, India
}

\section{Abstract}

Corona Virus Disease-2019 (COVID-19) has become one of the most serious diseases in the history of mankind. It has captured the entire world and solutions are yet to be discovered to fight this global crisis. The outcomes of COVID-19 are influenced by a variety of pre-existing factors. The secondary microbial infections are one of the prominent ones that are major contributors for Antimicrobial Resistance (AMR) as they warrant the use of antimicrobial medications. The present review aimed at exploring the potential relationship between AMR under such circumstances and COVID-19 related outcomes. The published literature across the globe has delineated that the impact of COVID-19 may have worsened by a great degree due to the presence of secondary infections majorly bacterial ones. The consequences of COVID-19 have been fatal and a significant proportion can be a major attributor to AMR, either directly or indirectly. Although, there is a dearth of studies that can establish a very strong and direct relationship between AMR and negative COVID-19 outcomes so in-depth research on this topic is required to further explain this relationship in detail.

\section{Introduction}

The COVID-19 Pandemic caused by SARS CoV-2 has affected millions of people worldwide. The chaos created by the disease has bagged the full focus, commitment and support from all governments, international institutions and organizations, the healthcare workforce, the private sector, civil society and the general public.

Coronaviruses belong to family Coronaviridae with potential of causing illness in humans and animals. These are enveloped viruses with +ssRNA as genetic material and are known to cause respiratory ailments ranging from the common cold to severe diseases such as Severe Acute Respiratory Syndrome (SARS) and Middle East Respiratory Syndrome (MERS) and present ongoing pandemic termed as COVID-19 [1]. The viral outbreak was reported to begin in Wuhan, China in late 2019. The most prevalent symptoms of the disease are dry cough, fever, tiredness, loss of taste or smell along with other less common or mild symptoms such as pains, headache, sore throat, diarrhoea or skin rashes etc. The disease mainly spread from person to person through droplets expelled during coughing, speaking or sneezing either from the mouth or through nose.

\section{More Information}

*Address for Correspondence: Dr. KP Mishra, Scientist-F, Defence Research and Development Organization (DRDO)-HQ, Delhi, 110054, India, Tel: +91 11 23810142; Fax: +91 1123810141 ; Email: kpmpgi@rediffmail.com

Submitted: February 10, 2021

Approved: February 24, 2021

Published: February 25, 2021

How to cite this article: Mishra KP, Mishra P, Singh AK, Singh SB. Impact of COVID-19 pandemic on anti-microbial resistance and secondary microbial infections. Int J Clin Virol. 2021; 5: 032-036.

DOI: 10.29328/journal.ijcv.1001032

Copyright: ( 2021 Mishra KP, et al. This is an open access article distributed under the Creative Commons Attribution License, which permits unrestricted use, distribution, and reproduction in any medium, provided the original work is properly cited.

Keywords: Antimicrobial resistance; COVID-19; Antibiotics; Inflammation; Viruses

Abbreviations: COVID-19: Coronavirus Disease 2019; AMR: Antimicrobial Resistance; SARS: Severe Acute Respiratory Syndrome; MERS: Middle East Respiratory Syndrome; SARSCoV-2: Severe Acute Respiratory Syndrome Coronavirus 2; +ssRNA: Positive single stranded RNA

A) Check for updates

OPEN ACCESS
Critically ill patients suffering with COVID-19 are more susceptible to hospital acquired infections and, thus, often require the aid of antibiotics. The extensive use of antibiotics and close contact with other patients in hospitals may lead to the spread of antimicrobial-resistant bacteria.

A weaker immune response during SARS CoV-2 infection may contribute to secondary bacterial infections and microbial co-infections may occur during viral infections [2]. Under such circumstances, rates of mortality and morbidity increases.

This raised a need for accurate diagnosis and appropriate antimicrobial drug therapy. Antibiotics are a class of antimicrobials used to treat bacterial infections, but they usually do not work against viruses. So antibiotics are ineffective for prophylaxis or treatment of viral infections. However, in critically ill patients or under several complications due to damage caused by virus, there is a need of antibiotic usage at some instances due to secondary bacterial infections [3]. Bacterial pneumonia under such conditions can be treated with antibiotics. Infection during H1N1 pandemic also, approximately $12 \%-19 \%$ of patients under hospitalization 
have developed pneumonia as a secondary bacterial infection $[4,5]$. Similarly, there are studies indicating the presence of secondary microbial infections, sepsis and septic shock in patients suffering from COVID-19 disease [6]. Consumption of antibiotics under such conditions may led to emergence of antimicrobial resistance. Critically ill patients are more prone to develop ventilator-associated pneumonia due to requirement of intensive care unit (ICU) which enhances the need of antibiotics several times [7].

The prophylactic and therapeutic use of antibiotics is very well documented. Several studies suggest the use of macrolide antibiotics such as azithromycin in early stages of COVID-19 infection due to their immunomodulatory, anti-inflammatory properties and ability to target viral replication $[8,9]$. Hantoushzadeh, et al. demonstrated that the consumption of antibiotics may be a possible cause of cytokine storm observed during COVID-19 due to stimulation of the immune cells to secrete pro-inflammatory cytokines such as, IL-6, TNF- $\alpha$ and IL-1 $\beta$ and enhanced levels of Toll-like receptors specially TLR4 after they recognize bacterial cell ligands $[10,11]$.

An increasing body of opinion is contemplating that the COVID-19 outcomes may be hampered by the presence of AMR or due to the presence of bacteria in lungs [12-14]. Such a condition elevates their potential to cause damage [15]. According to a recently published study, U.S. Department of Defense (DOD) is aiming to study the role of "secondary" infections (either bacterial or fungal) in patients suffering from COVID-19 and the role of antimicrobials to prevent them [3]. The use of antibiotics to treat viral illness has led to emergence in the rate of AMR among various pathogens.

The current review aims to explore potential connection between AMR, secondary infections and COVID-19 patient outcomes utilizing the data and papers available online on PubMed, Google Scholar and other scientific sources. The current review is based upon the evidences of relation between secondary microbial infections, AMR and COVID-19 outbreak impact.

\section{Relationship between COVID-19, AMR and secondary co-infections}

COVID-19 and the emergence of AMR: In 2014, World Health Organization has declared the global crisis of antibiotic resistance, a worldwide threat to public health which means this crucial defence is a dwindling resource. Many studies are cuing that most of the severe COVID-19 patients require antibiotics. Anti-bacterial medications such as Amoxicillin, Azithromycin and Clavulanate have been used in combination to treat COVID-19 patients with pneumonia under nonintensive care as significant number of patients is developing secondary infections.

According to a recent study, antibiotic prescription was required in $67 \%$ of the total COVID-19 patients. Among these patients, approximately $72 \%$ of them have no obvious signs of bacterial infection [16]. The commonly used antibiotics were azithromycin, vancomycin, cefepime and ceftriaxone. The rate of mortality and level of inflammatory markers was significantly high in patients who were given antibiotics in comparison to those who did not receive antibiotic therapy [16].

COVID-19 and secondary infections prevalence: A metaanalysis highlights the presence of bacterial co-infections in $7 \%$ of the hospitalized patients. The incidence may increase upto $14 \%$ in cases where only ICU patients were included in the study. This indicates that the changes of developing secondary infections increases with increase in severity of the COVID-19 [17,18].

Many studies also highlighted the incidence of Pulmonary Aspergillosis as a secondary infection in critical cases of putative COVID-19 disease [19-21]. Aspergillus is a drugresistant fungus, a common mold with abundance in both indoor and outdoor environment. The major cause of infection is microscopic Aspergillus spores which typically enters the circulation through the air while breathing. The infection is commonly found in patients with dwindled immunity, in contrast to otherwise healthy individuals with functioning immune system.

One study in Paris, reported Aspergillus infection in 33\% of COVID-19 patients [22]. Similar findings were also reported which delineates that $10-15 \%$ of COVID-19 patients had fungal or bacterial infection in their pulmonary system [6]. According to a study conducted on 135 adult patients confirmed for SARS-CoV-2 in Amphia Hospital Breda, the Netherlands, incidences of secondary infections including invasive pulmonary aspergillosis were reported in patients admitted in Intensive Care Unit (ICU) [23]. Approximately, one third of patients with severe COVID-19 infection requiring intensive care may also be battling another life-threatening infection: invasive aspergillosis, a deadly fungal super infection caused by Aspergillus mold. According to a case report, a 56 year old patient with SARS-CoV2 infection was found to be co infected with a triazole-resistant strain of $A$. fumigatus. The patient was suspected of bacterial pneumonia and thus received amoxicillin and pristinamycin for several days along with several other medications during hospitalization [24].

A retrospective cohort study encompassing the COVID-19 patients in Renmin Hospital of Wuhan University from Jan 1 to Feb 6, 2020 also depicts that Secondary bacterial infection is a common complication in COVID-19 patients. As many as $42 \%$ of the patients reported secondary bacterial infections [25]. A recent Lancet article encompassing data from two hospitals delineated that in Wuhan city of China, 50\% of patients who died had secondary infections whereas the prevalence of secondary infection was reported to be merely $0.73 \%$ in patients who survived. All these patients except one 
were treated with antibiotics [26]. The above-mentioned data forms a basis that the mortality was depending mostly upon the secondary infections and not on the COVID-19 infection. The scale of COVID-19 pandemic spread will surely upsurge the second slow-motion AMR pandemic behind it across the globe by whopping up antibiotic resistance, pathogens' adaptive ability to defend it against antibiotics.

Several independent researchers have dragged our attention towards the ill effects of AMR on COVID-19 outcomes.

Antibiotic resistance may become the cause of additional sickness and death across the globe as the toll of corona virus induced pneumonia stretches to ICU beyond their capacity. Thus, the prophylactic usage of antibiotics in COVID-19 cases may cause the emergence of resistant bacteria [27-31].

The spread of resistant bacteria in COVID-19 and other immunosuppressed patient can result into fatal consequences. "A significant number of the deceased COVID-19 patients had secondary bacterial infections which is common for several other viral infections. In severe viral respiratory infections, the immune system is weakened, and respiratory system exposed to other pathogens including opportunistic ones. In such cases, if a hospitalized patient is infected with resistant bacteria, consequences can be fatal. According to a study conducted at National University Hospital, Singapore, there was indications of increasing rates of resistant bacterial infections such as methicillin-resistant Staphylococcus aureus (MRSA) infections and bacteremia in hospitals during the outbreaks of novel emerging pathogens such as previously reported SARS. Although, the suspected reason for this pardoxical increase was change in conventional practices and measures to control infection [32].

It bears further investigation if the resistant bacteria have influenced the COVID-19 situation as evident in Italy, where hospitals have been shown to have significant "AMR-related problems". One retrospective review of COVID-19 death cases in Wuhan depicted that Bacterial infections can be an important factor in promoting the death of patients. Apart from the use of antimicrobial drugs to cure infections, their unnecessary or empirical use is also reported under the lack of rapid diagnostic tools that supports medical decision and also aids in clinical management of COVID-19 [33]. This poses numerous direct risks to the patient including various side effects and adversity events [34-37].

Streptococcus pneumoniae, is a major causal organism of pneumonia and other pneumococcal infections [38]. Azithromycin, a semi synthetic macrolide antibiotic is approved for pneumonia treatment as it offers the advantages in terms of tolerability, duration of administration in comparison to other macrolides [39]. Similarly, Amoxicillin and clavulanate is a combination antibacterial medicine used widely to treat such infections [40]. 30\% - 40\% of several common types of bacteria have already acquired resistance to the most commonly used class of drugs including macrolides such as azithromycin. Inappropriate use of these antibiotics could surely hamper their efficacy [3]. Unsurprisingly, resistance against such potential antimicrobial drugs poses a great challenge for the management of such infections in future. Similarly, use of antifungal for treating secondary fungal infections developed either in normal COVID-19 patients or in severely immunocompromied patients due to ongoing immunosuppressive medications or treatments as in case of cancer, HIV can potentially become a serious concern which increase in the pace of mortality and morbidity. So, they must be used wisely and strict control measures are needed further to prevent their misuse. Also, the use of investigational medications for COVID-19 must be allowed after ethically approved, randomized, controlled trials and its efficacy and safety for public health related aspects must be well considered. Several studies highlights the need for treating COVID-19 patients already existing in the market i.e. a situation called as Pharmaceutical repurposing as the pace of drug development and discovery is very slow and the cost associated with it is substantially high [41,42]. Under such conditions, the beneficial epidemiological, radiological, clinical and virologic characteristics underlying the disease must be well illustrated.

These studies support the fact that patients with severe COVID-19 infections are at a higher risk for developing such deadly, life threatening super infections. Although, there is a shortage of reliable therapeutics available to fight the disease, it is crucial that all the treatment strategies must be well evaluated and thoroughly studied otherwise it will lead to another pandemic or even a deadly storm.

Although, the availability of published literature on AMR and COVID-19 relation is very scarce and other pertaining aspects like age, gender, comorbidities, ethnicity, environment, quality of health services, species/family of bacteria or fungi etc have not been encompassed it is difficult to conclude the effect of COVID-19 outcomes on AMR and secondary infections.

\section{Conclusion}

AMR has been a slow-moving pandemic with long term side-effects across the world. It has always contributed negatively in the menace of life threatening conditions like HIV, cancer, during surgeries especially in immunocompromised patients. It may impact the COVID-19 patients leading to fatal consequences. A significant percentage of patients develop secondary microbial infections (either bacterial or fungal) during COVID-19 complications and the outcome of these patients has colossally impacted negatively by the already existing AMR. Although it's still too early to conclude a direct relationship between COVID-19 and emergence of AMR. The profuse use of antibiotics either alone or in combination with antivirals, antimalarial drugs during COVID-19 pandemic may potentially soar up the AMR which will surely create a vicious cycle of antibiotic usage, AMR and COVID-19 fatal outcomes. 


\section{Acknowledgment}

Priyanka Mishra thanks DRDO for providing financial support in the form of junior and senior research fellowship.

\section{References}

1. Zheng J. SARS-CoV-2: an emerging coronavirus that causes a global threat. Int J Biol Sci. 2020; 16: 1678-1685.

PubMed: https://pubmed.ncbi.nlm.nih.gov/32226285/

2. Mirzaei R, Goodarzi P, Asadi M, Soltani A, Aljanabi HA, et al. Bacterial co-infections with SARS-CoV-2. IUBMB life. 2020; 72: 2097-2111. PubMed: https://pubmed.ncbi.nlm.nih.gov/32770825/

3. Reardon S. Antibiotic treatment for COVID-19 complications could fuel resistant bacteria. Science. 2020.

4. Murray AK. The Novel Coronavirus COVID-19 Outbreak: Global Implications for Antimicrobial Resistance. Front Microbiol. 2020; 11; 1020. PubMed: https://www.ncbi.nlm.nih.gov/pmc/articles/PMC7237633/

5. Kim H. Outbreak of novel coronavirus (COVID-19): what is the role of radiologists? Eur Radiol. 2020; 18: 1-2.

PubMed: https://pubmed.ncbi.nlm.nih.gov/32072255/

6. Zhou P, Liu Z, Chen Y, Xiao Y, Huang X, Fan XG. Bacterial and fungal infections in COVID-19 patients: A matter of concern. Infect Control Hosp Epidemiol. 2020; 1-2.

PubMed: https://www.ncbi.nlm.nih.gov/pmc/articles/PMC7184139/

7. Koenig SM, Truwit JD. Ventilator-associated pneumonia: diagnosis, treatment, and prevention. Clin Microbiol Rev. 2006; 19: 637-657. PubMed: https://pubmed.ncbi.nlm.nih.gov/17041138/

8. Pani A, Lauriola M, Romandini A, Scaglione F. Macrolides and viral infections: focus on azithromycin in COVID-19 pathology. Int $\mathrm{J}$ Antimicrob Agents. 2020; 106053.

PubMed: https://pubmed.ncbi.nlm.nih.gov/32534189/

9. Firth A, Prathapan P. Azithromycin: The first broad-spectrum therapeutic. Eur J Med Chem. 2020; 112739.

PubMed: https://pubmed.ncbi.nlm.nih.gov/32871342/

10. Hantoushzadeh S, Aliabad RA, Norooznezhad AH. Antibiotics, pregnancy, and fetal mental illnesses: where is the link? Am J Obstet Gynecol. 2020; 222: 639-640.

PubMed: https://pubmed.ncbi.nIm.nih.gov/32017921/

11. Hantoushzadeh S, Norooznezhad AH. Inappropriate Antibiotic Consumption as a Possible Cause of Inflammatory Storm and Septic Shock in Patients Diagnosed with Coronavirus-19 Disease (COVID-19). Arch Med Res. 2020; 51: 347-348.

PubMed: https://pubmed.ncbi.nlm.nih.gov/32340759/

12. Kirchhelle et al. Opinion: Antibiotic Resistance Could Lead to More COVID-19 Deaths. Scientific American. 2020.

https://archive.Istmed.ac.uk/id/eprint/14112

13. Cassini A, Högberg LD, Plachouras D, Quattrocchi A, Hoxha A, et al Attributable deaths and disability-adjusted life-years caused by infections with antibiotic-resistant bacteria in the EU and the European Economic Area in 2015: a population-level modelling analysis. The Lancet Infect Dis. 2019; 19: 56-66.

PubMed: https://pubmed.ncbi.nlm.nih.gov/30409683/

14. Helsingin Sanomat. Antibioottien runsas käyttö saattaa selittää Italian koronavirus-kuolemien määrää. 2020. https://www.hs.fi/tiede/art-2000006464588.html

15. Bengoechea JA, Bamford CG. SARS-CoV-2, bacterial co-infections, andAMR:the deadlytrioinCOVID-19?EMBOMolMed.2020;12:e12560. PubMed: https://pubmed.ncbi.nlm.nih.gov/32453917/
16. Neto AG, Lo KB, Wattoo A, Salacup G, Pelayo J, et al. Bacterial Infections and Patterns of Antibiotic Use in Patients with COVID-19. J Med Virol. 20121; 93: 1489-1495.

PubMed: https://pubmed.ncbi.nlm.nih.gov/32808695/

17. Lansbury L, Lim B, Baskaran V, Lim WS. Co-infections in people with COVID-19: a systematic review and meta-analysis. J Infect. 2020; 81: 266-275.

PubMed: https://pubmed.ncbi.nlm.nih.gov/32473235/

18. Langford BJ, So M, Raybardhan S, Leung V, Westwood D, et al. Bacterial co-infection and secondary infection in patients with COVID-19: a living rapid review and meta-analysis, Clin Microbiol Infect. 2020; 26: 1622-1629.

PubMed: https://pubmed.ncbi.nlm.nih.gov/32711058/

19. Abdalla S, Almaslamani MA, Hashim SM, Ibrahim AS, Omrani AS. Fatal Coronavirus Disease 2019-associated Pulmonary Aspergillosis; A Report of Two Cases and Review of the Literature. IDCases. 2020. e00935. PubMed: https://pubmed.ncbi.nlm.nih.gov/32864340/

20. Lamoth F, Glampedakis E, Boillat-Blanco N, Oddo M, Pagani JL. Incidence of invasive pulmonary aspergillosis among critically ill COVID-19 patients. Clin Microbiol Infect. 2020; 26: 1706-1708. PubMed: https://pubmed.ncbi.nlm.nih.gov/32659385/

21. Verweij PE, Gangneux JP, Bassetti M, Brüggemann RJ, Cornely OA, et al. Diagnosing COVID-19-associated pulmonary aspergillosis. Lancet Microbe. 2020; 1: e53-55.

PubMed: https://pubmed.ncbi.nlm.nih.gov/32835328/

22. Alanio A, Delliere S, Fodil S, Bretagne S, Megarbane B. High prevalence of putative invasive pulmonary aspergillosis in critically ill COVID-19 patients. medRxiv. 2020.

23. Andreas L. E. van Arkel, Tom A. Rijpstra, 1 Huub N. A. Belderbos, 1 Peter van Wijngaarden, Paul E. Verweij and Robbert G. Bentvelsen COVID-19-associated Pulmonary Aspergillosis. Am J Respir Critical Care Med. 2020; 202: 132-135

PubMed: https://pubmed.ncbi.nlm.nih.gov/32396381/

24. Ghelfenstein-Ferreira T, Saade A, Alanio A, Bretagne S, de Castro RA, et al. Recovery of a triazole-resistant Aspergillus fumigatus in respiratory specimen of COVID-19 patient in ICU-A case report. Med Mycol Case Rep. 2020.

PubMed: https://pubmed.ncbi.nlm.nih.gov/32837880/

25. Wang L, He W, Yu X, Hu D, Bao M, et al. Coronavirus Disease 2019 in elderly patients: characteristics and prognostic factors based on 4-week follow-up. J Infect. 2020; 80: 639-645. PubMed: https://pubmed.ncbi.nlm.nih.gov/32240670/

26. Zhou F, Yu T, Du R, Fan G, Liu Y, et al. Clinical course and risk factors for mortality of adult in patients with COVID-19 in Wuhan, China: a retrospective cohort study. Lancet. 2020; 395: 1054-1062. PubMed: https://pubmed.ncbi.nlm.nih.gov/32171076/

27. Huang C, Wang Y, Li X, Ren L, Zhao J, et al. Clinical features of patients infected with 2019 novel coronavirus in Wuhan, China. Lancet. 2020; 395: 497-506.

PubMed: https://pubmed.ncbi.nlm.nih.gov/31986264/

28. Centers for Disease Control and Prevention (CDC). Bacterial coinfections in lung tissue specimens from fatal cases of 2009 pandemic influenza A (H1N1) - United States, May-August 2009. MMWR Morb Mortal Wkly Rep. 2009; 58: 1071-1074. PubMed: https://pubmed.ncbi.nlm.nih.gov/19798021/

29. Lupia T, Scabini S, Pinna SM, Di Perri G, De Rosa FG, et al. 2019 novel coronavirus (2019-nCoV) outbreak: A new challenge. J Glob Antimicrob Resist. 2020; 21: 22-27.

PubMed: https://pubmed.ncbi.nlm.nih.gov/32156648/ 
30. Wang Z, Yang B, Li Q, Wen L, Zhang R. Clinical Features of 69 Cases with Coronavirus Disease 2019 in Wuhan, China. Clin Infect Dis. 2020; 71: 769-777.

PubMed: https://pubmed.ncbi.nlm.nih.gov/32176772/.

31. WHO. Strategic preparedness and response plan for the new coronavirus. 2020. https://www.who.int/publications-detail/COVID-19strategy-update-13-april-2020

32. Chai LYA, Ng TM, Habib AG, Singh K, Kumarasinghe G, et al. Paradoxical Increase in Methicillin-Resistant Staphylococcus aureus Acquisition Rates Despite Barrier Precautions and Increased Hand Washing Compliance during an Outbreak of Severe Acute Repiratory Syndrome. Clin Infect Dis. 2005; 40: 632-633.

PubMed: https://www.ncbi.nlm.nih.gov/pmc/articles/PMC7107850/

33. Rawson TM, Ming D, Ahmad R, Moore LS, Holmes AH. Antimicrobia use, drug-resistant infections and COVID-19. Nat Rev Microbiol. 2020; 18: 409-410.

PubMed: https://pubmed.ncbi.nlm.nih.gov/32488173/

34. Li X, Wang L, Yan S, Yang F, Xiang L, et al. Clinical characteristics of 25 death cases with COVID-19: a retrospective review of medical records in a single medical center, Wuhan, China. Int J Infect Dis. 2020; 94: 128-132.

PubMed: https://pubmed.ncbi.nlm.nih.gov/32251805/

35. Yap FHY, Gomersall CD, Fung KSC, Ho PL, Ho OM, et al. Increase in methicillin-resistant Staphylococcus aureus acquisition rate and change in pathogen pattern associated with an outbreak of severe acute respiratory syndrome. Clin Infect Dis. 2004; 39: 511-516. PubMed: https://pubmed.ncbi.nlm.nih.gov/15356814/
36. European Centre for Disease Prevention and Control. ECDC country visit to Italy to discuss antimicrobial resistance issues. Stockholm: ECDC; 2017.

37. Cao J, Tu WJ, Cheng W, Yu L, Liu YK, et al. Clinical Features and Short-term Outcomes of 102 Patients with Corona Virus Disease 2019 in Wuhan, China. Clin Infect Dis. 2020; 71: 748-755.

PubMed: https://pubmed.ncbi.nlm.nih.gov/32239127/

38. Bergman $M$, Huikko $S$, Huovinen $P$, Paakkari $P$, Seppälä $H$, et al. Macrolide and azithromycin use are linked to increased macrolide resistance in Streptococcus pneumoniae. Antimicrob Agents Chemother. 2006; 50: 3646-3650.

PubMed: https://pubmed.ncbi.nlm.nih.gov/16940064/

39. Sanchez F, Mensa J, Martinez JA, García E, Marco F, et al. Is azithromycin the first-choice macrolide for treatment of communityacquired pneumonia? Clin infect Diseas. 2003; 36: 1239-1245. PubMed: https://pubmed.ncbi.nlm.nih.gov/12746768/

40. EvansJ,HannoodeeM,WittlerM.AmoxicillinClavulanate.InStatPearls. 2020. PubMed: https://pubmed.ncbi.nlm.nih.gov/30844191/

41. Panati K, Narala VR. COVID-19 outbreak: an update on therapeutic options. SN Compr Clin Med. 2020.

PubMed: https://www.ncbi.nlm.nih.gov/pmc/articles/PMC7110269/

42. Pushpakom S, lorio F, Eyers PA, Escott KJ, Hopper S, et al. Drug repurposing: progress, challenges and recommendations. Nat Rev Drug Discov. 2019; 18: 41-58. PubMed: https://pubmed.ncbi.nlm.nih.gov/30310233/ 